\title{
Techno-environmental Assessment for a Bio-methanol Integrated Plant Using Anaerobic Digestion Of OFMSW, Carbon Capture and Biomass Gasification
}

\author{
Aristide Giuliano, Enrico Catizzone*, Donatella Barisano, Francesco Nanna, Antonio Villone, Isabella De Bari, Giacinto \\ Cornacchia, Giacobbe Braccio
}

ENEA-Italian National Agency for New Technologies, Energy and Sustainable Economic Development, Trisaia Research Centre, I-75026, Rotondella, Italy

Corresponding Author Email: enrico.catizzone@enea.it

https://doi.org/10.18280/ti-ijes.632-421

Received: 26 January 2019

Accepted: 3 May 2019

\section{Keywords:}

biomass, OFMSW, waste valorization, biomethanol, techno-environmental assessment

\begin{abstract}
Production of energy or chemicals from biomass and several waste substrates appears a concrete strategy for replacing fossil fuels and reducing carbon dioxide emissions in the atmosphere. In particular, methanol from biomass or bio-waste is considered a reliable energy vector and key intermediate for industrial chemistry. Currently, methanol is industrially produced via syngas conversion using natural gas as the main feedstock. Biomethane produced via anaerobic digestion (AD) of Organic Fraction Municipal Solid Wastes (OFMSW) may be used as an alternative to natural gas for production of syngas with optimal composition via commercialized reforming processes. In this work, a technoenvironmental assessment for methanol production from biogas is presented and discussed. In particular, three case studies were assessed to minimize the environmental impact of biomethanol production.
\end{abstract}

\section{INTRODUCTION}

Methanol is one of the most important and versatile intermediate for the chemical industry. In fact, it may be used as building block for the synthesis of high value-added products such as acetic acid, anti-knock additives (e.g. MTBE), gasoline-cut hydrocarbons, light-olefins and dimethyl ether [1-7]. Furthermore, its use in the biodiesel production processes has been strongly investigated and commercialized.

More than 40 million tonnes per year of methanol are currently produced using several catalytic processes that use syngas (a mixture of $\mathrm{H}_{2}, \mathrm{CO}$ and $\mathrm{CO}_{2}$ ) as reactants. Methanol synthesis from syngas occurs through the following reactions:

$$
\begin{array}{ll}
\mathrm{CO}+2 \mathrm{H}_{2}=\mathrm{CH}_{3} \mathrm{OH} & \Delta \mathrm{H}_{298 \mathrm{~K}}=-90.55 \mathrm{~kJ} / \mathrm{mol}_{\mathrm{CH} 3 \mathrm{OH}} \\
\mathrm{CO}_{2}+3 \mathrm{H}_{2}=\mathrm{CH}_{3} \mathrm{OH}+\mathrm{H}_{2} \mathrm{O} & \Delta \mathrm{H}_{298 \mathrm{~K}}=-49.43 \mathrm{~kJ} / \mathrm{mol}_{\mathrm{CH} 3 \mathrm{OH}} \\
\mathrm{CO}_{2}+\mathrm{H}_{2}=\mathrm{CO}+\mathrm{H}_{2} \mathrm{O} & \Delta \mathrm{H}_{298 \mathrm{~K}}=+41.12 \mathrm{~kJ} / \mathrm{mol}
\end{array}
$$

In addition, side reactions such as methanation and coke formation take place.

Syngas required from the process is currently produced via reforming or gasification of fossil carbon sources, such as natural gas, coal or oil.

Due to environmental concerns, carbon emissions and fossil sources depletion, alternative carbon sources should be considered [7-19]. In this regard, biomass gasification (BG) may be an attractive route to produce syngas. The main drawback of this process is the low hydrogen content in the gas stream; in fact, the $\left(\mathrm{H}_{2}-\mathrm{CO}_{2}\right) /\left(\mathrm{CO}+\mathrm{CO}_{2}\right)$ molar ratio $(\mathrm{R})$ needed for the methanol synthesis that should be at least 2 requires downstream processes consisting in the gas clean-up and water gas shift reactions, in order to increase the hydrogen content in the syngas stream [16].
Biogas produced by anaerobic digestion of organic wastes represents an attractive renewable carbon source from both economic and environmental point of view [20-21]. Biogas is a mixture of methane and carbon dioxide with minor quantities of nitrogen, hydrogen sulfide and volatile organic compounds. Depending on the process conditions the $\mathrm{CH}_{4} / \mathrm{CO}_{2}$ molar ratio ranges from 1.1 to about 2.5. Biogas may be used as fuel in internal combustion engines although several technical/environmental concerns are involved. Usually, biogas is purified with a complex upgrading system to obtain high-pure bio-methane that may be used as automotive fuel [22]. A promising alternative utilization of bio-methane consists in the production of syngas by a reforming processes, such as dry reforming, steam reforming, partial oxidation or their combination (e.g., autothermal reforming, tri-reforming) [23]. Steam reforming of methane is the most commercialized and well-known technology for producing syngas. Although the huge amount of energy required from the process, steam reforming produces syngas with high hydrogen content, suitable for several industrial applications, such as methanol or ammonia synthesis. The hydrogenation of carbon dioxide represents a further alternative to produce methanol, as long as hydrogen is produced via electrolysis of water by using renewable energy sources [24-25]. In this way, both renewable energy and carbon dioxide may be stored in a high addedvalue liquid like methanol.

This work aims to simulate several cases for bio-methanol production involving several emerging technologies such as anaerobic digestion of organic fraction municipal solid waste for biogas production, biomass gasification, carbon capture, and water electrolysis. All the investigated scenarios are compared and discussed in terms of technical concerns and environmental impact, with the scope to give new perspectives 
for energy saving and greenhouse gas emissions mitigation.

\section{METHODS}

This section reports the process configurations investigated in this study and the methodology used to assess and analyze each case. All of the investigated cases are simulated taking as base an anaerobic digestion system able to treat about 10 tonnes/h of OFMSW.

\subsection{Anaerobic digestion for biogas production (AD)}

The anaerobic digestion (AD) system considered in this work was based on the works of Migliori et al. [24] and Li et al. [25] and it was not included in the process simulation but was considered for environmental aspects. The base of calculation was 10 tonnes/h of OFMSW (about $27 \mathrm{wt} \%$ of solid content) that are continuously pumped in a horizontal reactor keeping a residence time of about one month under mesophilic conditions. The produced gas containing methane, carbon dioxide and contaminants such as hydrogen sulfide and volatile organic compounds is assumed to be treated with an upgrading system consisting of chemical scrubbers, active carbon filters and membranes able to obtain highly purified bio-methane [24-25]. Based on data reported in the literature [25], the production of bio-methane from the above-described process should be about $500 \mathrm{Nm}^{3} / \mathrm{h}$. Digestate is assumed to be used for agricultural uses.

\subsection{Biomass gasification (BG)}

Gasification is a thermochemical process run at sub stoichiometric oxygen ratio able to convert solid fuel, such as biomass, in a gaseous stream that can be used for combined heat and power production, or as intermediate for chemicals production. In this work, the simulation was carried out based on data reported by Barisano et al. [28], obtained in a pilot scale internally circulating bubbling fluidized bed reactor using almond shells as biomass feedstock. More details about experimental set-up are reported in ref. [28]. Briefly, biomass is gasified at atmospheric pressure and $820-880{ }^{\circ} \mathrm{C}$ by using steam $/ \mathrm{O}_{2}$ mixture as gasification agent. Both char and tar present in the reactor out-stream are abated with ceramic filter and wet scrubber, respectively. The gas stream from the gasification unit is assumed to be cleaned from residual tars and sulfur compounds obtaining a mixture with the average composition reported in Table 1:

Table 1. Composition of the bio-syngas stream of gasification unit (\%vol $\left.{ }_{\text {DRY }}\right)$

\begin{tabular}{ccccc}
\hline $\mathbf{C O}$ & $\mathbf{H}_{\mathbf{2}}$ & $\mathbf{C O}_{\mathbf{2}}$ & $\mathbf{C H}_{\mathbf{4}}$ & $\mathbf{N}_{\mathbf{2}}$ \\
\hline 28 & 32 & 25 & 10 & 5 \\
\hline
\end{tabular}

\subsection{Process description for methanol production}

As previously reported, bio-methane (BM) produced via anaerobic digestion may be reformed for producing syngas with a $\mathrm{H}_{2} / \mathrm{CO}$ equals to about 3 . Both practical and theoretical evidence suggest that a $\mathrm{R}$ value as low as 2 may be considered optimal for methanol synthesis [29]. The aim of this work is to investigate three different scenarios for bio-methanol production. In particular, steam reforming of bio-methane was coupled to three different processes in order to obtain the optimal $\mathrm{R}$ value required for methanol synthesis, with the main scope to reduce $\mathrm{CO}_{2}$ emission. In particular, the following three cases were assessed:

(1). BM-SR coupled to biomass gasification: biomass gasification produces syngas with a low $\mathrm{R}$ value not suitable for methanol synthesis. Such syngas stream is mixed with syngas produced via bio-methane reformed syngas (BM-SR) aiming to obtain the optimal $R$ value (i.e., 2). A scheme of the process is reported in Figure 1a.

(2). BM-SR with partial utilization of $\mathrm{AD}-\mathrm{CO}_{2}$ for methanol synthesis: the $\mathrm{CO}_{2}$ produced from OFMSW anaerobic digestion was captured and added to BM-SR stream to obtain the optimal $R$ value. A scheme of the process is reported in Figure $1 \mathrm{~b}$.

(3). BM-SR with total utilization of $\mathrm{AD}-\mathrm{CO}_{2}$ for methanol synthesis: in that case, water electrolysis was considered for the production of the required hydrogen to have the optimal $\mathrm{R}$ value for methanol synthesis. It was assumed that renewable energy (e.g., solar energy) is used for the electrolysis unit. A scheme of the process is reported in Figure 1c. An alternative way to use the $\mathrm{CO}_{2}$ produced from $\mathrm{AD}$, may be the direct tri-reforming of biogas, but this aspect is not considered in this paper.

\subsection{Process simulation for methanol production}

To simulate different processes of section 2.3, the process simulation software CHEMCAD was used. Redlich-KwongSoave thermodynamic equation of state was adopted to simulate high-pressure systems, while NRTL-RK was used for distillation columns and flash separation units.

(1) Production of syngas from OFMSW

Yield of OFMSW to biogas was set equal to $0.5 \mathrm{t} / \mathrm{t}_{\text {OFMSW }}$ (Table 2).

Biogas (40\%vol $\mathrm{CO}_{2}-60 \%$ vol methane) was compressed to 12 bar (by an isoentropic compressor) and sent to the membranes (ideal separator), where high-pure methane was obtained. Steam Reforming (SR) reaction was considered as at equilibrium at $850{ }^{\circ} \mathrm{C}$ and 30 bar by an equilibrium reactor. Steam to carbon ratio in $\mathrm{SR}\left(\mathrm{t}_{\mathrm{S}} / \mathrm{t}_{\mathrm{CH} 4}\right)$ equal to 3.4 was considered. Heat duty to have SR reaction at fixed temperature was obtained burning purge gas (Figure 1).

(2) Syngas from biomass

Biomass gasification data were obtained from Barisano et al. [28] Pure oxygen (312 $\left.\mathrm{kg}_{\mathrm{O} 2} / \mathrm{t}_{\text {biomass }}\right)$ and steam (440 $\left.\mathrm{kg} / \mathrm{t}_{\text {biomass }}\right)$ were used in the gasifier in order to obtain syngas with a low nitrogen content. In the simulation, it was assumed that bio-syngas leaves the gasifier at about $750{ }^{\circ} \mathrm{C}$ and atmospheric pressure and upgraded obtaining a clean stream with the composition reported in Table 1 .

(3) $\mathrm{MeOH}$ production

Syngas stream obtained in the three different cases was compressed to 80 bar, mixed with recycle stream, cooled down to $200{ }^{\circ} \mathrm{C}$ and fed to the methanol synthesis adiabatic reactor. An equilibrium reactor was adopted for the methanol synthesis unit by considering the reactions reported in the introduction part. A pressure drop equal to 2 bar was assumed along the reactor. 


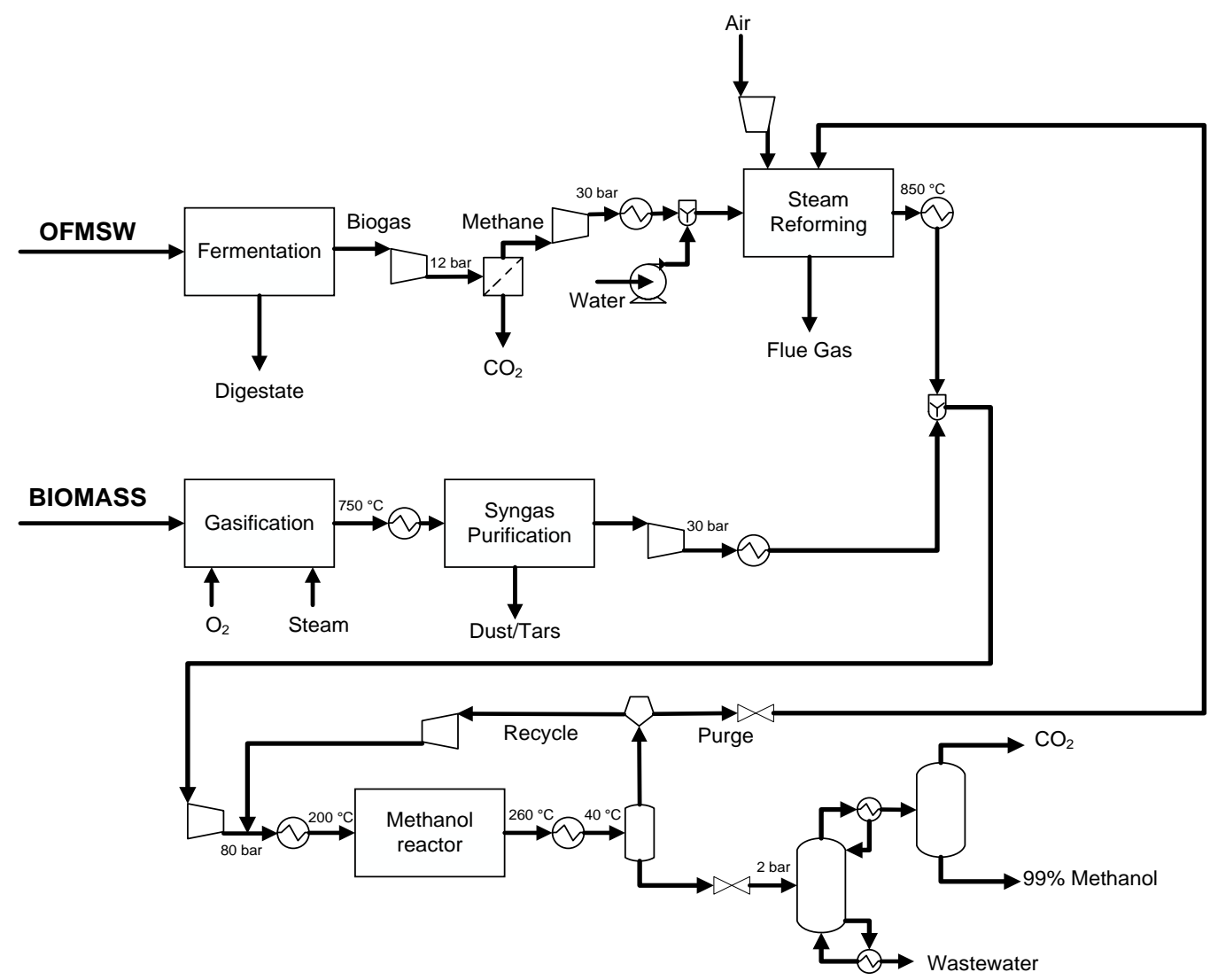

(a)

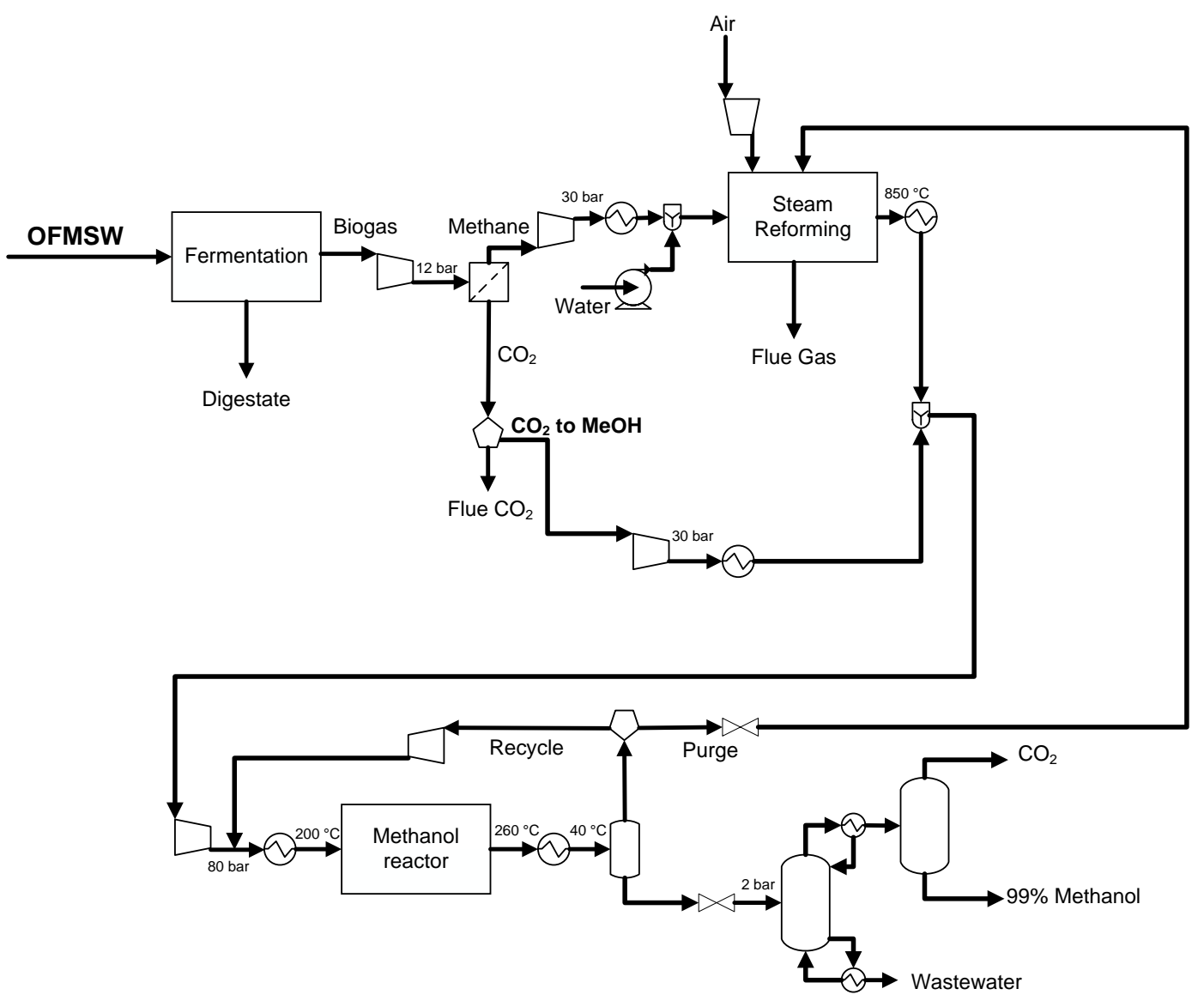

(b) 


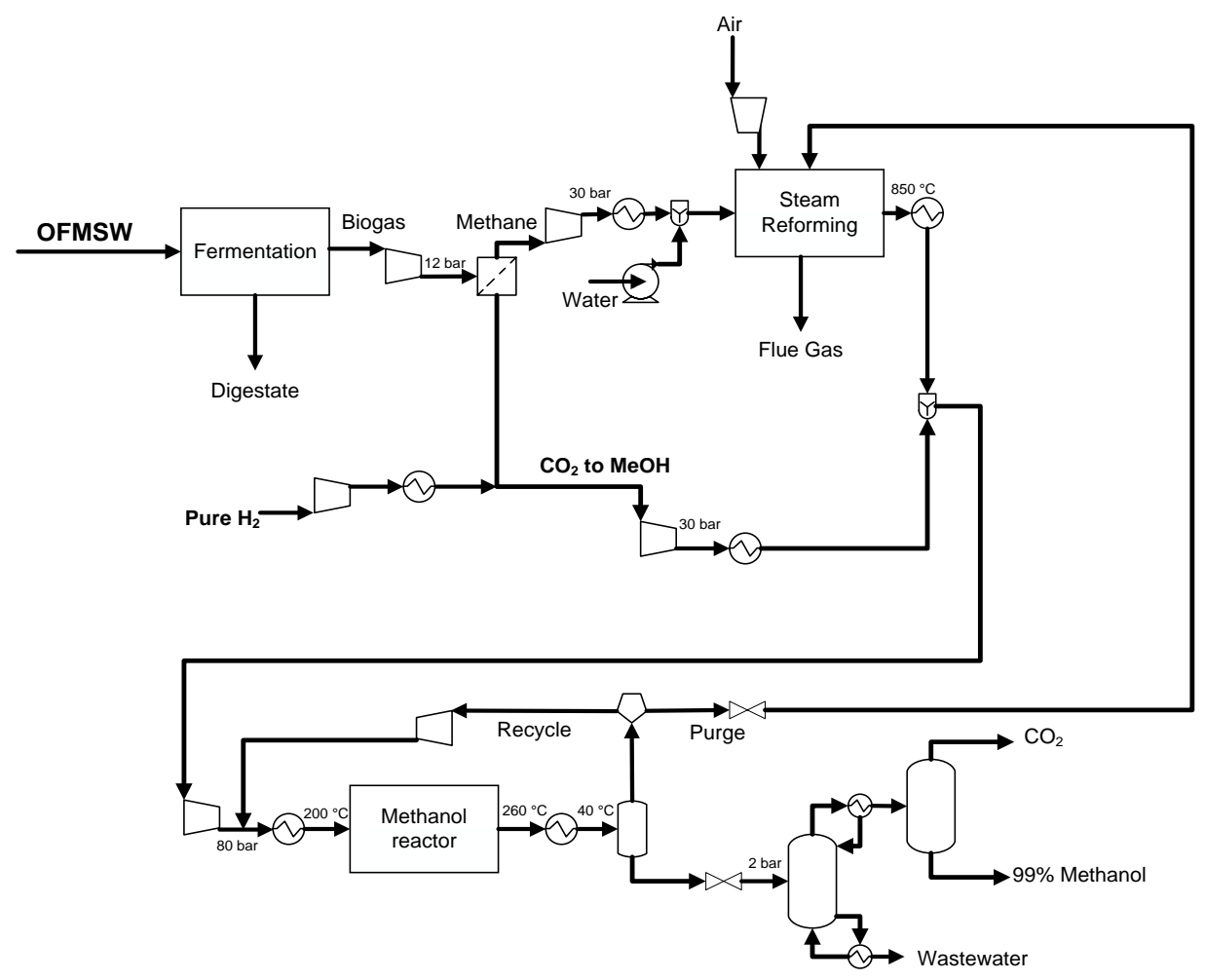

(c)

Figure 1. Process flowsheet for: a) case $1-$ Biomass gasification; b) case $2-\mathrm{CO}_{2}$ captured; c) case $3-\mathrm{CO}_{2}$ captured + pure hydrogen

(4) Recycle and $\mathrm{MeOH}$ purification

Reactor outstream was cooled to $40{ }^{\circ} \mathrm{C}$ and pre-purified in a flash phase-separator where light gases are separated and partially recycled. The purge stream was used as fuel for SR reactor while recycle stream was recompressed to 80 bar and mixed to fresh syngas stream. For this purpose, 2 bar compressed air with an excess of $100 \%$ respect to the stoichiometric amount was used.

The liquid stream, mainly containing methanol and water, was expanded in a throttling valve until 2 bar and distilled to produce a $\mathrm{MeOH}$ rich stream from the top and wastewater from the bottom. The distillate was further purified in a flash phase-separator to obtain a $99 \% \mathrm{MeOH}$ stream. 2.

More details of the process simulation are reported in Table

Table 2. Process simulation parameters

\begin{tabular}{|c|c|c|c|}
\hline $\begin{array}{l}\text { OFMSW flowrate } \\
(\mathrm{t} / \mathrm{h})\end{array}$ & 10 & $\begin{array}{l}\text { MeOH reactor } \\
\text { pressure (bar) }\end{array}$ & 80 \\
\hline $\begin{array}{c}\text { Biogas yield } \\
(\mathrm{t} / \text { tofMSw })\end{array}$ & 0.5 & $\begin{array}{l}\text { Biomethane membrane } \\
\text { temperature }\left({ }^{\circ} \mathrm{C}\right)\end{array}$ & 40 \\
\hline Membrane & & & \\
\hline $\begin{array}{l}\text { biomethane recovery } \\
(\%)\end{array}$ & 100 & SR temperature $\left({ }^{\circ} \mathrm{C}\right)$ & 850 \\
\hline $\begin{array}{c}\text { Biomethane purity } \\
(\%)\end{array}$ & 100 & $\begin{array}{l}\text { Biomass syngas } \\
\text { temperature }\left({ }^{\circ} \mathrm{C}\right)\end{array}$ & 750 \\
\hline $\begin{array}{l}\text { Steam to carbon ratio } \\
\text { in SR }\left(\mathrm{ts}_{\mathrm{s}} / \mathrm{t}_{\mathrm{CH}} 4\right)\end{array}$ & 3.4 & $\begin{array}{l}\mathrm{MeOH} \text { reactor inlet } \\
\text { temperature }\left({ }^{\circ} \mathrm{C}\right)\end{array}$ & 200 \\
\hline $\begin{array}{c}\text { Biomass syngas yield } \\
(\mathrm{t} / \mathrm{tDRY})\end{array}$ & 1.07 & Columns pressure (bar) & 2 \\
\hline $\begin{array}{l}\text { Biomethane } \\
\text { membrane pressure } \\
\text { (bar) }\end{array}$ & 12 & $\begin{array}{l}\text { Recycle condenser } \\
\text { temperature }\left({ }^{\circ} \mathrm{C}\right)\end{array}$ & 40 \\
\hline SR pressure (bar) & 30 & $\begin{array}{c}\text { Stoichiometric ratio } \\
\text { air/purge }\end{array}$ & 2 \\
\hline
\end{tabular}

\subsection{Environmental impact analysis}

For each process case, a final environmental impact analysis was performed in terms of total $\mathrm{CO}_{2}$-equivalent emission by adopting the values reported in Table 3 . In particular, a negative $\mathrm{CO}_{2}$-equivalent emission value is associated with both biomass and OFMSW, by considering the $\mathrm{CO}_{2}$ absorbed from the atmosphere by biomass and the $\mathrm{CO}_{2}$ emitted from the landfill for organic waste disposal, respectively.

Table 3. $\mathrm{CO}_{2}$-equivalent emission parameters

\begin{tabular}{cc}
\hline Process item & Set-up value \\
Electricity $\left(\mathrm{kg}_{\mathrm{CO} 2 \mathrm{eq}} / \mathrm{MWhe}\right)[29]$ & 600 \\
Biomass feedstock $\left(\mathrm{kg}_{\mathrm{CO} 2 \mathrm{eq}} / \mathrm{t}\right)[30]$ & -1449 \\
OFMSW $\left(\mathrm{kg}_{\mathrm{CO} 2 \mathrm{eq}} / \mathrm{t}\right)[31]$ & -1597 \\
Wastewater $\left(\mathrm{kg}_{\mathrm{CO} 2 \mathrm{eq}} / \mathrm{t}\right)[29]$ & 500 \\
Pure oxygen $\left(\mathrm{kgCO}_{\mathrm{eq}} / \mathrm{t}\right)[32]$ & 282 \\
Process water $\left(\mathrm{kg}_{\mathrm{CO} 2 \mathrm{eq}} / \mathrm{t}\right)[29]$ & 6.5 \\
Pure hydrogen $\left(\mathrm{kg}_{\mathrm{CO} 2 \mathrm{eq}} / \mathrm{t}\right)[33]$ & 2400 \\
\hline
\end{tabular}

Furthermore, the environmental impact estimated for the investigated bio-methanol production plants was compared with the that associated with the production of methanol from fossils, that is about $915 \mathrm{~kg}_{\mathrm{CO} 2 \mathrm{eq}} / \mathrm{t}_{\mathrm{MeOH}}$ [34]

\section{RESULTS}

In this paragraph and in Table 4 the main results of the three scenarios investigated are reported.

\subsection{Case 1}

The simulation of bio-methanol production by adopting the 
plant configuration of Case 1 reveals that about $1.8 \mathrm{t} / \mathrm{h}$ of biomass is requested for effective methanol production. In fact. In such conditions, the gasification unit produces about $2 \mathrm{t} / \mathrm{h}$ of bio-syngas with the composition reported in Table 1. By mixing that stream with the syngas produced from SR of biomethane, about $9.7 \mathrm{t} / \mathrm{h}$ of syngas with $\mathrm{R}=2.8$ is obtained. $\mathrm{R}$ value of the stream at the reactor inlet is set to 2 by recycle stream. Under such conditions, the outlet temperature of the methanol synthesis reactor was $267{ }^{\circ} \mathrm{C}$ with productivity of purified methanol of $3.06 \mathrm{t} / \mathrm{h}$.

Furthermore, the high LHV of purge stream allows having a low purge to recycle ratio $(4 \%)$ able to provide the thermal energy requested by steam reforming of bio-methane.

Concerning the theoretical electrical consumption, the production of bio-methanol requires about $4.4 \mathrm{MWe}$, mainly related to compressors. In particular, biogas compressor until 12 bar $(0.5 \mathrm{MWe})$, biomass-syngas compressor until 30 bar $(0.5 \mathrm{MWe})$, the compressor of fresh feed of methanol reactor (1.1 MWe) and SR furnace compressors (2.2 MWe) were the main high-consumption equipments.

\subsection{Case 2}

For case 2, the syngas produced via SR of bio-methane was enriched with about $1.3 \mathrm{t} / \mathrm{h}$ of $\mathrm{AD}-\mathrm{CO} 2$, to obtain a syngas stream with a $\mathrm{R}=2$. The obtained syngas stream leads to the production of $2.28 \mathrm{t} / \mathrm{h}$ of purified methanol. Furthermore, due to higher $\mathrm{CO}_{2}$ concentration, a lower LHV is calculated for purge stream respect to case 1 . Therefore, a higher purge ratio, such as $7 \%$, is requested to thermally support the steam reforming reactor, causing a process efficiency loss.

Lower electricity consumption (4.0 MWe) than in the previous case was obtained thanks to a lower reactor inlet flowrate to compress and the lack of syngas compressor.

\subsection{Case 3}

For case 3, all of the captured $\mathrm{AD}-\mathrm{CO}_{2}$ (about $3.2 \mathrm{t} / \mathrm{h}$ ) is used for methanol synthesis. In that case, as previously described, hydrogen has to be produced in order to ensure $\mathrm{R}=2$ at the reactor inlet. Under such conditions, about $3.9 \mathrm{t} / \mathrm{h}$ of purified methanol is produced, mainly because of the high syngas flowrate available for the reaction. On the other hand, high electricity consumption was calculated for the compressor of reactor fresh feed (about 1.6 MWe). Also the $\mathrm{CO}_{2}$ and pure hydrogen compressors (about $0.9 \mathrm{MWe}$ ) lead to high consumption of electricity. The process water consumption was the highest, compared to case 1 and 2, because of the water to send to water electrolysis (about 2.2 $\mathrm{t} / \mathrm{h})$.

Table 4. Main process results

\begin{tabular}{cccc}
\hline Case & $\mathbf{1}$ & $\mathbf{2}$ & $\mathbf{3}$ \\
\hline Bio-syngas from BG $(\mathrm{t} / \mathrm{h})$ & 2 & 0 & 0 \\
Pure oxygen to gasification $(\mathrm{kg} / \mathrm{h})$ & 584 & 0 & 0 \\
Steam to gasification $(\mathrm{kg} / \mathrm{h})$ & 824 & 0 & 0 \\
Captured $\mathrm{CO}_{2}$ to methanol $(\mathrm{t} / \mathrm{h})$ & 0 & 1.3 & 3.2 \\
Pure hydrogen to methanol $(\mathrm{t} / \mathrm{h})$ & 0 & 0 & 0.24 \\
$\mathrm{R}$ & 2.01 & 2.05 & 2.06 \\
MeOH production $(\mathrm{t} / \mathrm{h})$ & 3.06 & 2.28 & 3.39 \\
Purge ratio $(\%)$ & 4 & 7 & 6 \\
Electricity consumption $(\mathrm{MWe})$ & 4.4 & 4.0 & 5.4 \\
Process water consumption $(\mathrm{t} / \mathrm{h})$ & 6.8 & 5.9 & 8.1 \\
\hline
\end{tabular}

\section{DISCUSSION}

As reported in previous sections, three alternative cases for bio-methanol production were assessed via computer-aided simulation. Results showed that an AD plant able to process about $10 \mathrm{t} / \mathrm{h}$ of OFMSW might be integrated with a gasification unit to produce bio-methanol. In this case, both waste and biomass may be used with an OFMSW/biomass weight ratio of about $5: 1$. The gasification of biomass by using oxygen/steam as gasification agents allows obtaining a syngas mixture useable for the process, due to low nitrogen content. Air-based gasification would be not suitable for such kind of integration. Because the high pressures requested by methanol synthesis, high compression power and large equipment volumes would be needed due to nitrogen presence. On the other hand, oxygen/steam-based gasification is not a wellknown technology and several aspects are still under debate such as temperature control, optimal reactor configuration and so on. Furthermore, the gas stream produced by gasification has to be upgraded in order to obtain a clean syngas for catalysis. Although this aspect was not deeply considered in this work, there are several technologies already at the state of the art that can be used for proper gas cleaning [30]. As reported in Table 5, the process proposed in Case 1 is a characterized of $\mathrm{CO}_{2}$ emission as low as about $2 \mathrm{ktCO}_{2} \mathrm{eq} / \mathrm{y}$ mainly related to the utilization of biomass as feedstock that is assumed to able to absorb about $20 \mathrm{ktCO}_{2} \mathrm{eq} / \mathrm{y}$. The last value may be used as trade-off value for assessing the type of biomass to be used in the process.

Table 5. Main environmental results $\left(\mathrm{ktCO}_{2} \mathrm{eq} / \mathrm{y}\right)$

\begin{tabular}{cccc}
\hline Case & $\mathbf{1}$ & $\mathbf{2}$ & $\mathbf{3}$ \\
\hline OFMSW & -120 & -120 & -120 \\
Digestate & 60 & 60 & 60 \\
Flue gas & 18 & 18 & 19 \\
Wastewater & 18 & 17 & 21 \\
CO2 from fermentation & 24 & 15 & 0 \\
Electricity & 20 & 18 & 24 \\
Biomass & -20 & 0 & 0 \\
Pure oxygen & 2 & 0 & 0 \\
Pure hydrogen & 0 & 0 & 4 \\
Total & 2 & 9 & 9 \\
\hline
\end{tabular}

Table 6. Comparison between the environmental impact of fossil-based methanol and biomethanol of 3 cases

\begin{tabular}{cc}
\hline Case & $\mathbf{k g}_{\mathbf{C O 2 e q}} / \mathbf{t}_{\mathbf{M e O H}}$ \\
\hline 1 & 78 \\
2 & 517 \\
3 & 337 \\
Fossil methanol & 915 \\
\hline
\end{tabular}

When biomass is not used as co-feedstock, the equivalent emission of $\mathrm{CO}_{2}$ strongly increases, although some of the carbon dioxide produced during the anaerobic digestion process is reused for methanol synthesis. In particular, when Case 2 is considered, only $9 \mathrm{kt}_{\mathrm{CO} 2} / \mathrm{y}$ may be used for methanol synthesis. No significant technological challenges are implied in the process configuration of Case 2 . In the last case, all the $\mathrm{CO}_{2}$ produced from anaerobic digestion plant is used for methanol production but hydrogen has to be produced via water electrolysis by using renewable energy.

The $\mathrm{CO}_{2}$ emission values reported in Table 6 show that all of the investigated cases may be considered an alternative to the traditional process for methanol synthesis from natural gas. 
In particular, when biomass is used as co-feedstock, the $\mathrm{CO}_{2}$ emitted strongly reduced, even if such aspect depends on the type of biomass used.

\section{CONCLUSIONS}

In this work, different process configurations for biomethanol synthesis have been simulated and discussed. From an environmental point of view, methanol may be produced starting from OFMSW, via anaerobic digestion followed by steam reforming of bio-methane for producing syngas. These systems may be integrated with biomass gasification, carbon dioxide capturing and hydrogen production, to reduce the $\mathrm{CO}_{2}$ footprint. Obtained results showed that, in terms of...., the investigated cases might be considered alternative to the traditional process for methanol production starting from natural gas. However the technologies selected for the three selected cases strongly differ in terms of technological maturity and related costs. Case 2 offers some more advantages with respect to the other scenarios: it is less complex in terms of technological platform, even if it produced higher $\mathrm{CO}_{2}$ emissions. A more detailed investigation, either technological and economic, is necessary to get a more reliable assessment of the more profitable case.

\section{REFERENCES}

[1] Olah GA. (2005). Beyond oil and gas: The methanol economy. Angew. Chem. Int. Ed 44(18): 2636-2639. https://doi.org/10.1002/anie.200462121

[2] Tian P, Wei Y, Ye M, Liu Z. (2015). Methanol to Olefins (MTO): From fundamentals to commercialization. ACS Catal 5(3): 1922-1938 https://doi.org/10.1021/acscatal.5b00007

[3] Catizzone E, Bonura G, Migliori M, Frusteri F, Giordano $\mathrm{G}$. (2018). $\mathrm{CO}_{2}$ recycling to dimethyl ether: state-of-theart and perspectives. Molecules 23(1): 31-58. https://doi.org/10.3390/molecules23010031

[4] Catizzone E, Migliori M, Purita A, Giordano G. (2019). Ferrierite vs. $\gamma-\mathrm{Al}_{2} \mathrm{O}_{3}$ : The superiority of zeolites in terms of water-resistance in vapour-phase dehydration of methanol to dimethyl ether. J. Energ. Chem 30: 162-169. https://doi.org/10.1016/j.jechem.2018.05.004

[5] Bonura G, Migliori M, Frusteri L, Cannilla C, Catizzone E, Giordano G, Frusteri F. (2018). Acidity control of zeolite functionality on activity and stability of hybrid catalysts during DME production via $\mathrm{CO}_{2}$ hydrogenation. J. $\quad \mathrm{CO}_{2} \quad$ Util 24: 398-406. https://doi.org/10.1016/j.jcou.2018.01.028

[6] Catizzone E, Deale SV, Bianco M, Michele DA, Aloise A, Migliori M, Valtchev V, Giordano G. (2018). Catalytic application of ferrierite nanocrystals in vapourphase dehydration of methanol to dimethyl ether. Appl. Catal. B: Env 243: 273-282. https://doi.org/10.1016/j.apcatb.2018.10.060

[7] Giuliano A, Poletto M, Barletta D. (2015). Process design of a multi-product lignocellulosic biorefinery. Comp. Aided Chem. Eng. 37: 1313-1318. https://doi.org/10.1016/B978-0-444-63577-8.50064-4

[8] Sofia D, Giuliano A, Poletto M, Barletta D. (2015). Techno-economic analysis of power and hydrogen coproduction by an IGCC plant with $\mathrm{CO}_{2}$ capture based on membrane technology. Comp. Aided Chem. Eng. 37: 1373-1378. https://doi.org/10.1016/B978-0-444-635778.50074-7

[9] Giuliano A, Poletto M, Barletta D. (2018). Pure hydrogen co-production by membrane technology in an IGCC power plant with carbon capture. Int. J. Hydrogen Energ. 43(41): 9279-19292. https://doi.org/10.1016/j.ijhydene.2018.08.112

[10] Giuliano A, Cerulli R, Poletto M, Raiconi G, Barletta D. (2016). Process pathways optimization for a lignocellulosic Biorefinery production levulinic acid, succinic acid, and ethanol. Ind. Eng. Chem. Res 55(40): 10699-10717. https://doi.org/10.1021/acs.iecr.6b01454

[11] Dincer I. (2000). Renewable energy and sustainable development: A crucial review Renew. Sust. Energ. Rev 4(2): $\quad$ 157-175. https://doi.org/10.1016/S13640321(99)00011-8

[12] Panwar NL, Kaushik SC, Kothari S. (2011). Role of renewable energy sources in environmental protection: A review. Renew. Sust. Energ. Rev 15(3): 1513-1524. https://doi.org/10.1016/j.rser.2010.11.037

[13] Salvi BL, Subramanian KA, Panwar NL. (2013). Alternative fuels for transportation vehicles: A technical review. Renew. Sust. Energ. Rev 25: 404-419. https://doi.org/10.1016/j.rser.2013.04.017

[14] Dusselier M, Mascal M, Sels BF. (2014). Top chemical opportunities from carbohydrate biomass: A chemist's view of the biorefinery. Top. Curr. Chem. 353: 1-40. https://doi.org/10.1007/128_2014_544

[15] Clarck JH. (2007). Green chemistry for the second generation biorefinery-sustainable chemical manufacturing based on biomass. J. Chem. Technol. Biotechnol. 82(7): 603-609. https://doi.org/10.1002/jctb.1710

[16] Sutton D, Kelleher B, Ross JRH. (2001). Review n literature on catalysts for biomass gasification. Fuel Process. Technol 73(3): 155-173. https://doi.org/10.1016/S0378-3820(01)00208-9

[17] Saxena RC, Adhikari DK, Goyal HB. (2000). Biomassbased energy fuel through biochemical routes: A review. Renew. Sust. Energ. Rev 13(1): 167-178. https://doi.org/10.1016/j.rser.2007.07.011

[18] Gunaseelan VN. (1997). Anaerobic digestion of biomass for methane production: a review. Biomass Bioenerg 13(1-2): $\quad 83-114$. https://doi.org/10.1016/S09619534(97)00020-2

[19] Mao C, Feng Y, Wang X, Ren G. (2015). Review on research achievements of biogas from anaerobic digestion. Renew. Sust. Energ. Rev 45: 540-555. https://doi.org/10.1016/j.rser.2015.02.032

[20] Miltner M, Makaruk A, Harasek M. (2017). Review on available biogas upgrading technologies and innovations towards advanced solutions. J.Clean. Prod 161: 13291337. https://doi.org/10.1016/j.jclepro.2017.06.045

[21] Dincer I, Acar C. (2015). Review and evaluation of hydrogen production methods for better sustainability. Int. J. Hydrogen Energ. 40(34): 11094-11111. https://doi.org/10.1016/j.ijhydene.2014.12.035

[22] Perathoner S, Centi G. (2014). $\mathrm{CO}_{2}$ recycling: A key strategy to introduce green energy in the chemical production chain. ChemSusChem 7(5): 1274-1282. https://doi.org/10.1002/cssc.201300926

[23] Quadrelli EA, Centi G, Duplan JL, Perathoner S. (2011). Carbon dioxide recycling: Emerging large-scale 
technologies with industrial potential. ChemSusChem 4(9): 1194-1215. https://doi.org/10.1002/cssc.201100473

[24] Migliori M, Catizzone E, Giordano G, Pera LA, Sellaro M, Lista, A, Zanardi G, Zoia L. (2019). Pilot plant data assessment in anaerobic digestion of organic fraction of municipal waste solids. Processes 7(1): 54-63. https://doi.org/10.3390/pr7010054

[25] Li Y, Park SY, Zhu J. (2011). Solid-state anaerobic digestion for methane production from organic waste. Renew. Sust. Energ. Rev 15(1): 821-826. https://doi.org/10.1016/j.rser.2010.07.042

[26] Barisano D, Canneto G, Nanna F, Alvino E, Pinto G, Villone A, Carnevale M, Valerio V. (2016). Steam/oxygen biomass gasification at pilot scale in a $n$ internally circulating bubbling fluidized bed reactor. Fuel $\begin{array}{lll}\text { Process. } & \text { Technol. 141: }\end{array}$ https://doi.org/10.1016/j.fuproc.2015.06.008

[27] da Silva ARG, Giuliano A, Errico M, Rong BG, Barletta D. (2019). Economic value and environmental impact analysis of lignocellulosic ethanol production: assessment of different pretreatment processes. Clean Technol. Environ. Policy 21(3): 637-654. https://doi.org/10.1007/s10098-018-01663-Z

[28] Galanopoulos C, Odierna A, Barletta D, Zondervan E. (2017). Design of a wheat straw supply chain network in Lower Saxony, Germany through optimization. Comput. Aided Chem. Eng. 40: 871-876. https://doi.org/10.1016/B978-0-444-63965-3.50147-1

[29] Perez J, Andres MJD, Lumbreras J, Rodriguez E. (2018). Evaluating carbon footprint of municipal solid waste treatment: Methodological proposal and application to a case study. J. Clean. Prod 205. https://doi.org/10.1016/j.jclepro.2018.09.103
[30] Vita A, Italiano C, Previtali D, Fabiano C, Palella A, Freni F, Bozzano G, Pino L, Manenti F. (2018). Methanol synthesis from biogas: A thermodynamic analysis. Renew. Energ. 18: 673-684. https://doi.org/10.1016/j.renene.2017.11.029

[31] Sun Q, Li H, Yan J, Liu L, Yu Z, Yu X. (2015). Selection of appropriate biogas upgrading technology-a review of biogas cleaning, upgrading and utilization. Renew. Sus. Energ. $\quad$ Rev 51: 521-532. https://doi.org/10.1016/j.rser.2015.06.029

[32] Alsultanny YA, Al-Shammari NN. (2014). Oxygen specific power consumption comparison for air separation units. Eng. J 18(2): 67-80. https://doi.org/10.4186/ej.2014.18.2.67

[33] Bareiß K, de la Rua C, Möckl M, Hamacher T. (2019). Life cycle assessment of hydrogen from proton exchange membrane water electrolysis in future energy systems. Appl. $\quad$ Energ. 327: 862-872. https://doi.org/10.1016/j.apenergy.2019.01.001

[34] Li J, Ma X, Liu H, Zhang X. (2018). Life cycle assessment and economic analysis of methanol production from coke oven gas compared with coal and natural gas routes. J. Clean. Prod 185: 299-308. https://doi.org/10.1016/j.jclepro.2018.02.100

\section{NOMENCLATURE}

$\mathrm{AD}$

OFMSW

BM-SR

BG
Anaerobic Digestion

Organic Fraction Municipal Solid Waste Bio-Methane Steam Reforming Biomass Gasification 